\title{
Aging of wood under long-term storage in a salt environment
}

\author{
J. Tintner ${ }^{1}$ - E. Smidt ${ }^{1} \cdot$ J. Tieben ${ }^{1} \cdot$ H. Reschreiter ${ }^{2}$ • \\ K. Kowarik ${ }^{2}$ M. Grabner ${ }^{1}$
}

Received: 23 July 2015/Published online: 11 May 2016

(C) The Author(s) 2016. This article is published with open access at Springerlink.com

\begin{abstract}
Aging of archeological wood in a salt environment was assessed in Hallstatt, Upper Austria, where Bronze Age wooden findings of the archeological salt mining site were compared with recent wood samples from the same site. Three species (Picea abies, Abies alba and Fagus sylvatica) were investigated. Recent samples covered all main geological units within the salt valley. FTIR spectroscopy was used to determine differences in wood chemistry. Principal component analysis was used to display the segregation of the data set according to the different factors and to give a measure of the strength of the effects. Results revealed that deacetylation processes took place at the wood material. The aging process affects wood chemistry significantly stronger than differences in earlywood and latewood. Together these two factors accounted for $80 \%$ of data variability. As a third factor, the tree species segregated the data set. Geological differences in the sampling sites were not mirrored in the FTIR spectra.
\end{abstract}

\section{Introduction}

Organic matter usually undergoes a rapid transformation process in our environment. Depending on the recalcitrance of the molecules, mineralization and humification take place within days to few years after exposure. Several conditions can inhibit these processes and lead to subfossil materials. Dry (deserts), cold (ice, permafrost) and wet (groundwater, lake sediments, bogs and moors) conditions are favorable to keep good preservation, but also salt or some metal oxides can prevent

\section{E. Smidt}

ena.smidt@boku.ac.at

1 Department of Material Sciences and Process Engineering, University of Natural Resources and Life Sciences, Vienna, Austria

2 Department of Prehistory, Natural History Museum, Vienna, Austria 
aging processes (Jacomet and Kreuz 1999). Archeological wood samples found in marine sediments are, for example, the wrecks of the Swedish "Wasa" (Rowell and Barbour 1990)—sank in 1628 and salvaged in the harbor of Stockholm 1961-the English "Mary Rose" — sank in 1545 and salvaged 1982-or the two Russian frigates St. Mikael and St. Nikolai—sank in 1747 and 1790 and salvaged in the Gulf of Finland (Reunanen et al. 1989, 1990).

The salt mine in Hallstatt, Upper Austria, housed prehistoric mining activities during the Bronze Age (1500-1100 BC) and the Early Iron Age (850-350 BC). Due to a geological disaster, both mines were filled with material. Huge amounts of soil, stones and whole trees liquidated the mining activities. Since that time, all organic material was covered by salt-rich clay. Since the nineteenth century, the prehistoric mines have been studied and therefore excavated. The high amount of organic findings gives reason for the high value of the archeological site of Hallstatt. Very rare insights into prehistoric life are possible due to textiles, wood handicrafts, leather, excrements and other findings, which usually are rotted and decomposed in other sites (Kern et al. 2009; Reschreiter 2013). In the salt environment, microbial activity can be seen as negligible (Sorokin et al. 2013). The good preservation of the findings regarding shape and even colors suggests that no aging process at all has taken place. Among the organic findings in Hallstatt, wood plays a special role due to the high number of wood pieces and the good status of preservation (Grabner et al. 2010). The latter allows dating by dendrochronology. Up to now, no study assessed the chemistry of these wood findings.

Fourier transform infrared (FTIR) spectroscopy is a proven method to assess wood and its main compounds lignin, cellulose and hemicellulose (Costa e Silva et al. 1999; Meder et al. 1999; Pandey 1999), but also other wood compounds. Attenuated total reflection (ATR) is a special technique which allows to measure surfaces directly and point by point. It combines two advantages. Influences due to sample preparation with milling are avoided (Schwanninger et al. 2004), and earlywood can be measured separately if it is large enough (Mohebby 2008; Müller et al. 2009).

It was the target of this study to reveal the influence of a salt environment over a period of 3500 years on wood chemistry. Better knowledge of wood preservation or degradation under special environmental conditions can complement archeological findings and support data interpretation. In order to clearly detect changes due to aging, other effects such as differences in earlywood and latewood and the tree species (Emandi et al. 2011) or heterogeneity of the geological underground and differences in the orographic origin (Rana et al. 2008) were taken into account.

\section{Materials and methods}

Recent and prehistoric wood samples were taken in Hallstatt, Upper Austria. Altogether, 120 wood cores were measured. The heterogeneity of the geological situation in the salt valley of Hallstatt was covered by wood samples of trees grown on all important geological zones which are limestone, depleted Haselgebirge and a mixture of both (Mandl et al. 2012). Haselgebirge is the predominant breccia rock of 
the salt deposit in Hallstatt, containing mainly chlorides, clay, gypsum and carbonates. Depleted Haselgebirge is the cover material at the top, where rainwater leached mainly chlorides and gypsum. Furthermore, trees from different orographic origin were sampled (650 and about $1000 \mathrm{~m}$ asl.).

Only earlywood was measured from Picea abies and Abies alba. Both prehistoric and recent samples of Fagus sylvatica had such narrow tree rings that it was not possible to measure earlywood-like tissue separately. Therefore, 18 samples of prehistoric and recent samples of Picea abies with narrow tree rings were chosen and additionally measured at the whole ring to quantify this effect.

Sixty-eight cores from living Picea abies, 32 from living Abies alba and 20 from living Fagus sylvatica as well as 39 cores from archeological findings were analyzed (Table 1). Recent core samples were taken by random sampling of living trees on the respective geological underground. Cores with $5.5 \mathrm{~mm}$ diameter were taken using usual forestry increment borers, dried at room temperature, and polished on one side. Prehistoric samples were taken from inside the archeological mining site with the help of a machine-driven hollow corer. All findings were introduced into the mine either by Bronze Age men as mine timber or during a mass movement together with debris. In both cases, one can be quite sure that wood came locally from the high valley of the salt mine as the transport of huge logs would have been very complicated. Drilling cores with $7 \mathrm{~mm}$ diameter were taken, dried at room temperature, and polished on one side. Storage conditions in the mine can be described as follows: The wood was embedded in mass movement material. This material consists of partly depleted Haselgebirge with water contents between 10 and $15 \%$ DM. The wood was stored under wet conditions with a saturated salt solution in its pores. The salt consists of $95 \% \mathrm{NaCl}$. The solution features a $\mathrm{pH}$ slightly above 7 . Other inorganic compounds play only a subordinate role.

Fourier transform infrared (FTIR) spectroscopy was applied to characterize wood samples. Eight to twelve measurements were taken along the core samples which were fixed between the sample holder and the optical crystal of a Bruker ${ }^{\circledR}$ Helios FTIR micro sampler (Tensor 27). This device allows spot measurements with a spatial resolution down to $250 \mu \mathrm{m}$. The replicates were necessary to account for the variability due to the different age of the trees. FTIR spectra were recorded in the ATR (attenuated total reflection) mode in the mid infrared area $\left(4000-400 \mathrm{~cm}^{-1}\right)$.

Table 1 Sample numbers of different tree species and regions; all samples of FS are measured on narrow tree rings, PA and AA only on earlywood; numbers of PA behind the slash are additional samples measured with narrow tree rings

\begin{tabular}{llll}
\hline Origin & FS (Fagus sylvatica) & PA (Picea abies) & AA (Abies alba) \\
\hline Prehistoric samples & 9 & $10 / 10$ & 10 \\
DMW (depleted Haselgebirge) & 4 & $10 / 8$ & 11 \\
BLW (mixture with limestone) & 4 & 10 & \\
HWS (limestone) & 3 & 10 & 11 \\
HLA (mixture with limestone, 350 m & & 10 & \\
$\quad$ lower) & & & \\
\hline
\end{tabular}


Thirty-two scans were collected at a spectral resolution of $4 \mathrm{~cm}^{-1}$. The replicates of the spectra were vector normalized and averaged.

Principal component analysis (PCA) was performed with The Unscrambler ${ }^{\circledR} \mathrm{X}$ 10.1 software to display the influencing factors.

\section{Results and discussion}

\section{All samples}

Spectral regions from 3485 to $2430 \mathrm{~cm}^{-1}$ and from 1838 to $400 \mathrm{~cm}^{-1}$ were included in the analysis as these regions potentially contribute to any separation. Two main effects separated the samples into four sets: age and whether only earlywood or a mixture with latewood was measured. The spectral region from 1118 to $895 \mathrm{~cm}^{-1}$ had a main impact on the separation. This spectral region contains prominent $\mathrm{C}-\mathrm{O}$ bands of cellulose (Fengel and Ludwig 1991). The intensity of the cellulose band is influenced by the aging process (Fig. 2), but additionally by the tree species. In order to improve the assignment of the PCs to the different effects, the region was therefore excluded from PCA. Figure 1 displays the resulting PCA. PC 1 explains $57 \%$ of data variability and separates the data set into two groups with a clear distance in between which indicates a strong distinguishing effect. These two groups represent the prehistoric samples on the one side and all recent samples on the other side with no exception (Fig. 1a). Therefore, the loadings plot of PC 1 explains differences in the spectra reasoned by age of the sample groups. The loadings plot displays four strong spectral regions influencing PC 1: the $\mathrm{OH}-$ stretching region from 3000 to $3300 \mathrm{~cm}^{-1}$ and two comparatively narrow maxima at 1730 and $1235 \mathrm{~cm}^{-1}$ (Fig. 1e). In Fig. 1b, the same scores plot is shown, but the data set is marked according to the type of measurement. The second PC can be assigned to differences in measurement (only earlywood vs. narrow tree rings with a mixture of earlywood and latewood). The PC explains $23 \%$ of data variability. To display this effect more clearly, the prehistoric samples were removed in a second step (Fig. 3). Figure 1c again shows the same scores plot, but in this case arranged according to the tree species. Abies alba (AA) and Picea abies (PA) samples are well mixed. The separation of Fagus sylvatica (FS) samples can be reasoned at least partly by measuring only narrow rings at these samples. Further details are discussed in combination with Fig. 4. Finally, in Fig. 1d, data are arranged according to the sampling site (corresponding to different geological underground). For this factor, no obvious segregation was found.

Figure 2 visualizes the effect on the $\mathrm{OH}$-stretching region. Average spectra are shown of all prehistoric and all recent samples. The peak maximum shifts from 3350 (recent samples) to $3306 \mathrm{~cm}^{-1}$ (prehistoric samples), but the whole peak shifts from 2930 to $3358 \mathrm{~cm}^{-1}$. The region from 3200 to $3700 \mathrm{~cm}^{-1}$ is assigned to $\mathrm{OH}$ vibrations (Fengel 1993). The shift of the peak could be explained by the higher amount of $\mathrm{OH}$ bonds remaining after a deacetylation process (Stefke et al. 2008). The region from 1709 to $1738 \mathrm{~cm}^{-1}$ (including $1730 \mathrm{~cm}^{-1}$ ) can be assigned to the $\mathrm{C}=\mathrm{O}$ stretch in unconjugated ketones, carbonyl stretching vibration of the acetyl group of 

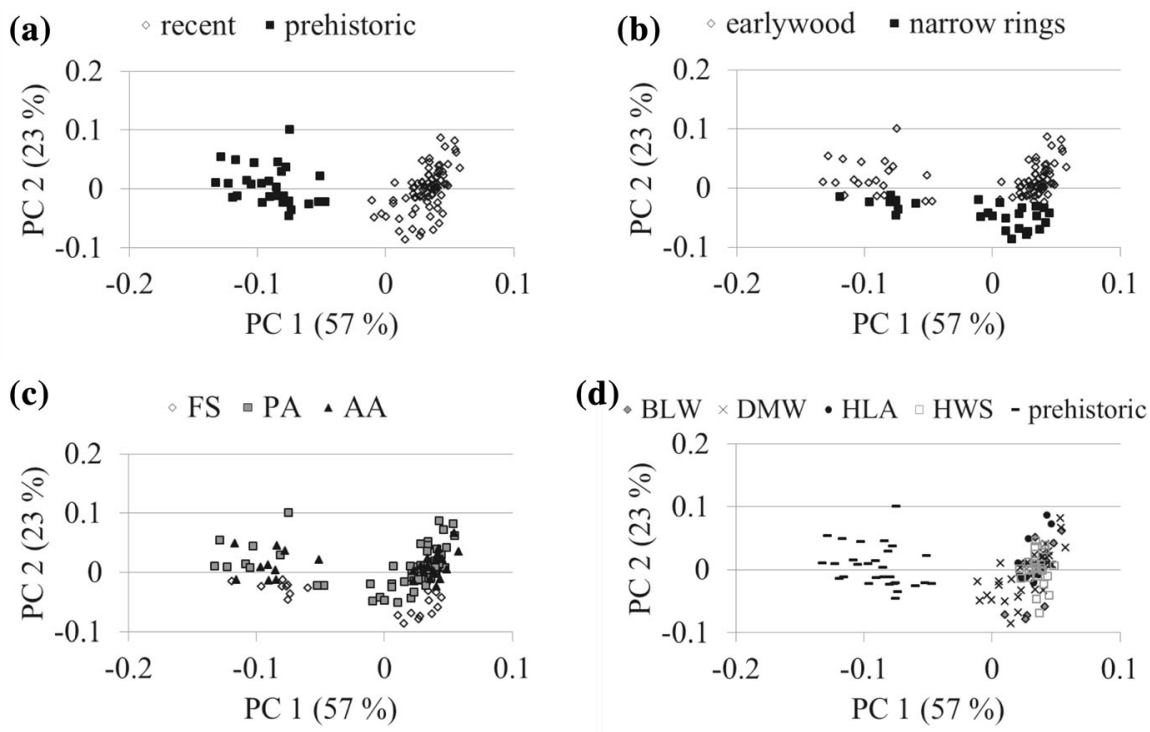

(e)

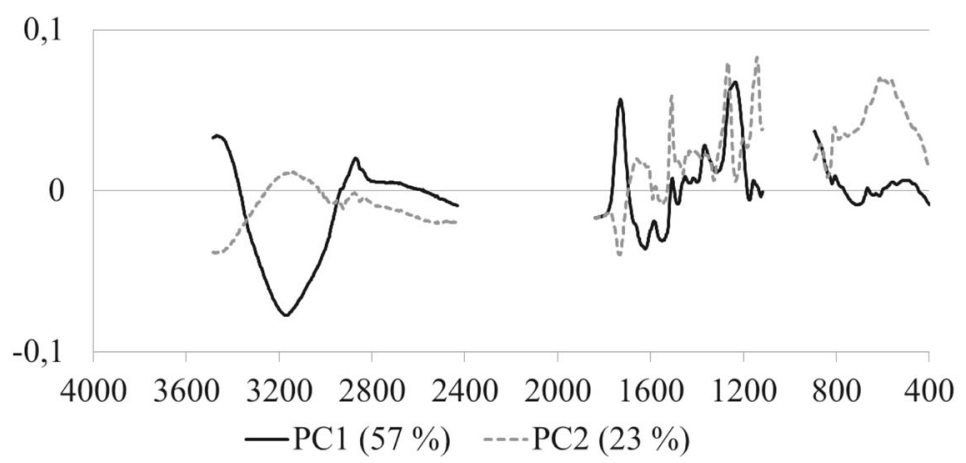

Fig. 1 PCA of all 120 samples; scores plot with the samples marked up according to (a) age, (b) measurement type, (c) tree species, and (d) sampling site, (e) displays the loadings plot of the first two PCs

hemicellulose (Terpáková et al. 2012) and in ester groups frequently of carbohydrate origin (Faix 1991). It is assumed that hemicelluloses degraded by breaking acetyl groups in xylan (Esteves et al. 2013). The region from 1225 to $1235 \mathrm{~cm}^{-1}$ origins from the $\mathrm{OH}$ vibration (deformation in plane), also from $\mathrm{COOH}$ (Fengel and Ludwig 1991). The decrease of this band can also be assigned to deacetylation processes (Mohebby 2008; Stefke et al. 2008). Pizzo et al. (2015) also found a decrease of the bands at 1730 and $1230 \mathrm{~cm}^{-1}$ when they assessed waterlogged wood samples by ATR-FTIR spectroscopy. Stich (2006) compared recent and waterlogged wood of Pinus sylvestris. The waterlogged samples were found in the sediment of a lake in Finland. Based on spectroscopic and chemical results, he concluded that after 4000-5000 years of storage in situ hydrolysis had taken place. Similar results were found for prehistoric Sequoia and Sequoiadendron wood under comparable storage conditions (Uçar et al. 2005). 


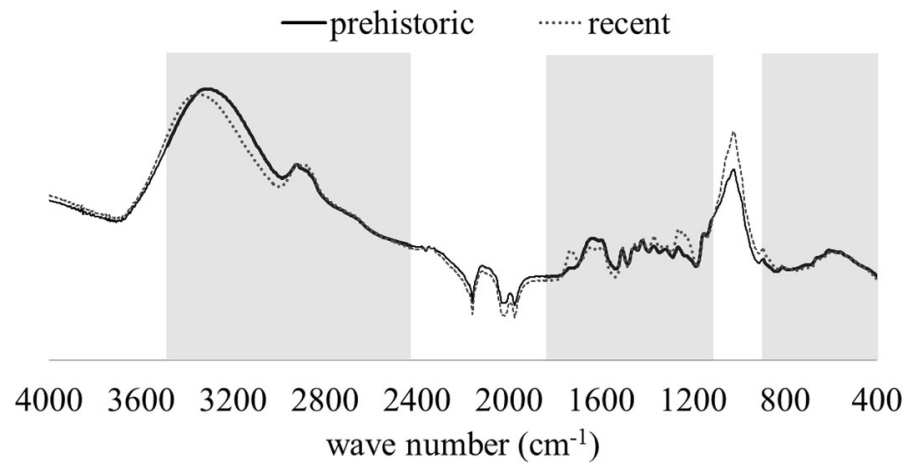

Fig. 2 Averaged FTIR spectra of the prehistoric and recent samples, gray boxes indicate the regions included in the PCA

\section{Only recent samples}

For a better assignment of the factor "type of measurement," prehistoric samples were excluded from the data matrix and PCA was recalculated. This changed the orientation of the data set. Results are presented in Fig. 3. The first PC explains $58 \%$ of data variability and separates the measurements of narrow tree rings and those of only earlywood. The loadings plot (Fig. 3c) displays three maxima at 1510,

(a) narrow rings - earlywood

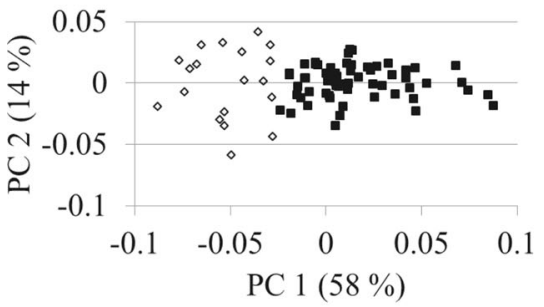

(b) $\triangle$ BLW $\square$ DMW $\triangle$ HLA $\times$ HWS

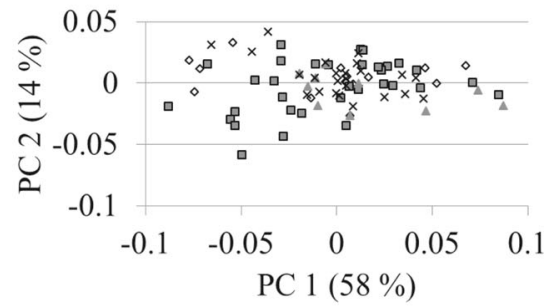

(c)

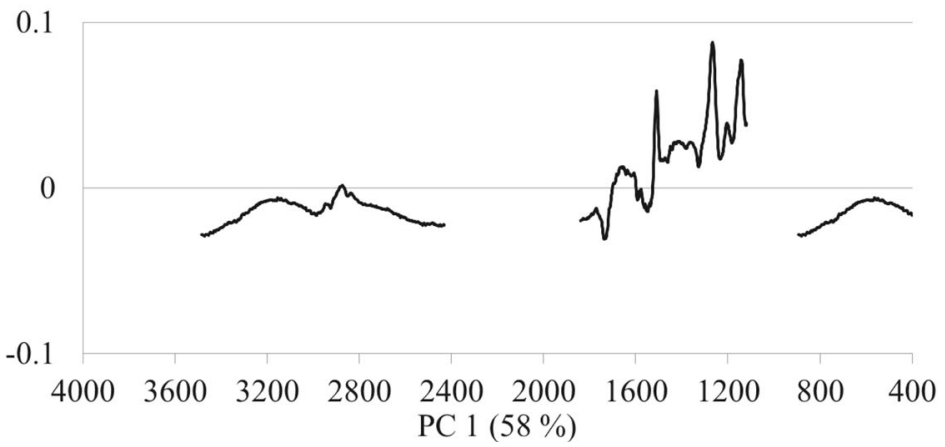

Fig. 3 PCA of recent 81 samples; scores plot with the samples marked up according to (a) measurement type and (b) sampling site, (c) displays the loadings plot of the first principal component 
1267 and $1140 \mathrm{~cm}^{-1}$, which are all linked to lignin (Faix 1991). The loadings of PC 1 in this PCA correspond well to the loadings of PC 2 in Fig. 1e. This can be expected, as the factor "type of measurement" is relevant in both cases. The factor "sampling site" cannot be found in the data structure even in this PCA (Fig. 3b).

\section{Only narrow rings}

Tree species result in different chemical wood composition. Differences in the ratio of lignin/cellulose/hemicelluloses, but also differences in extractives lead to different spectral patterns. To prove the effect of the factor "tree species," the samples with only earlywood (Picea abies and Abies alba) and the samples with narrow rings (Picea abies and Fagus sylvatica) were analyzed separately. The softwood species Picea abies and Abies alba were not separated (PCA not shown), but Picea abies and Fagus sylvatica differed strongly as displayed in Fig. 4. PC 1 explains $47 \%$ of data variability and mainly segregates the two species. No specimen overlaps the two groups. As displayed in the loadings plot, maxima at 1730 and $1230 \mathrm{~cm}^{-1}$ and minima at 1510 and $1270 \mathrm{~cm}^{-1}$ are mainly responsible for the segregation. Rana et al. (2008) investigated beech spectra and found (in the region of Fig. 4b) typical peaks at 1730, 1596, 1505, 1462, 1425, 1375, 1330 and $1235 \mathrm{~cm}^{-1}$. Müller et al. (2009) investigated beech and fir samples and found in the softwood the corresponding peaks at 1738 (weaker than in beech), 1505, 1460, 1372, 1320 (as a shoulder from 1350 similar to Fig. 4b) and $1267 \mathrm{~cm}^{-1}$. These
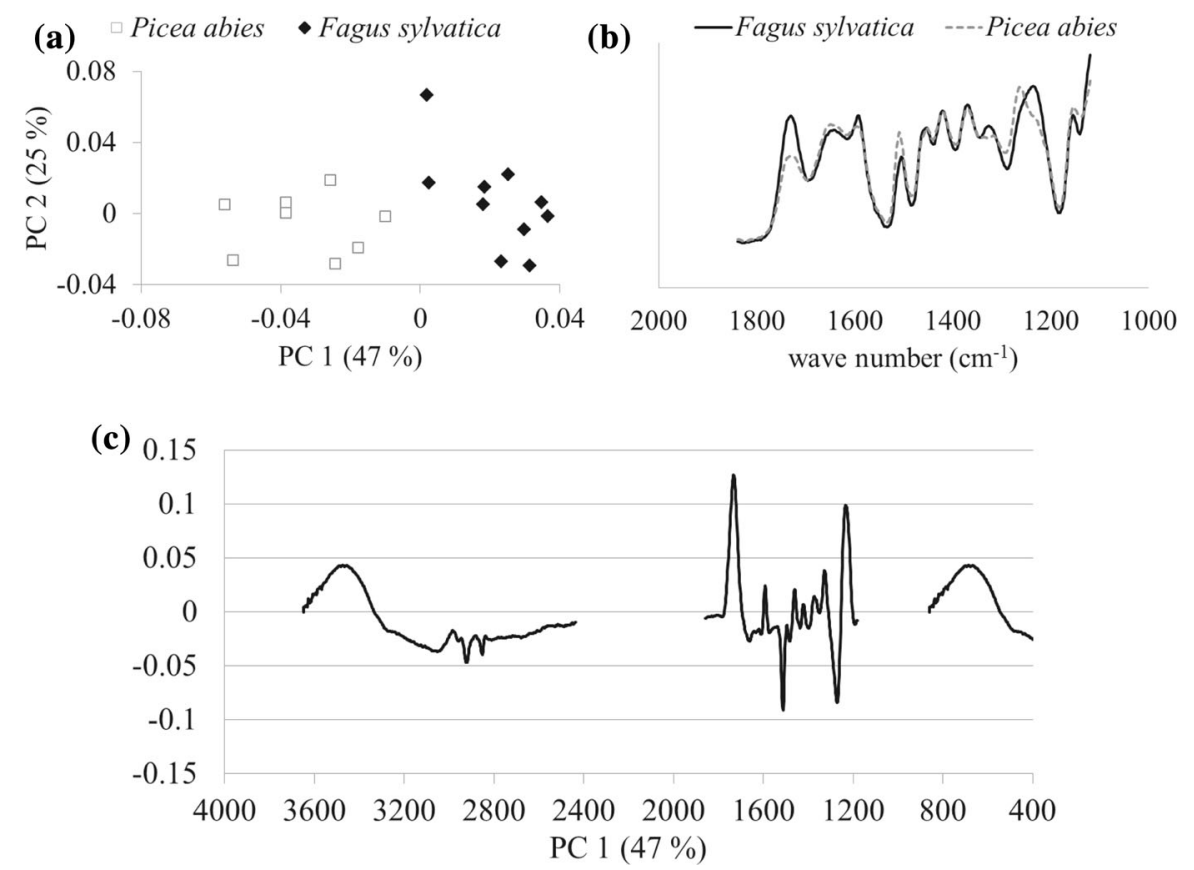

Fig. 4 PCA and IR spectra of recent 19 samples with narrow rings; (a) scores plot with the samples marked up according to the tree species; (b) averaged IR spectra in the wave number range from 1120 to $1838 \mathrm{~cm}^{-1}$; and (c) loadings plot of the first principal component 
results correspond to the result given in Fig. 4c, especially the peaks at 1730, 1270 and $1230 \mathrm{~cm}^{-1}$.

\section{Conclusion}

Aging of archeological wood by long-term storage in a salt environment leads to specific changes in wood chemistry. Deacetylation and degradation of hemicelluloses are the most probable processes responsible. In FTIR spectra, this leads on the one hand to a reduction of the bands in the region of 1730 and $1235 \mathrm{~cm}^{-1}$, and on the other hand to a shift of the whole $\mathrm{OH}$-region from 3000 to $3300 \mathrm{~cm}^{-1}$. The deacetylation process may cause an increased susceptibility to microbial attack against the archeological wood findings. This conclusion can be deduced from the converse effect of acetylation. The effect of aging is the most important one influencing FTIR spectra being responsible for $57 \%$ of data variability. Further $27 \%$ accounted for the factor of earlywood and narrow tree rings, where earlywood and latewood were measured together. Only as the third important factor the tree species segregated the data set. Differences in the geological underground of the sampling sites were not found in the corresponding wood spectra.

Acknowledgments Open access funding provided by University of Natural Resources and Life Sciences Vienna (BOKU). The samples for this work were taken in the course of the FWF project ISOwood PP23647. We are grateful to the forest owner for the sampling permission.

Open Access This article is distributed under the terms of the Creative Commons Attribution 4.0 International License (http://creativecommons.org/licenses/by/4.0/), which permits unrestricted use, distribution, and reproduction in any medium, provided you give appropriate credit to the original author(s) and the source, provide a link to the Creative Commons license, and indicate if changes were made.

\section{References}

Costa e Silva J, Nielsen BH, Rodrigues J, Pereira H, Wellendorf H (1999) Rapid determination of the lignin content in Sitka spruce (Picea sitchensis (Bong.) Carr.) wood by Fourier transform infrared spectrometry. Holzforschung 53:597-602

Emandi A, Vasiliu CI, Budrugeac P, Stamatin I (2011) Quantitative investigation of wood composition by integrated FT-IR and thermogravimetric methods. Cellul Chem Technol 45:579-584

Esteves B, Marques AV, Domingos I, Pereira H (2013) Chemical changes of heat treated pine and eucalypt wood monitored by FTIR. Maderas: Ciencia y Tecnologia 15:245-258

Faix O (1991) Classification of lignins from different botanical origins by FT-IR spectroscopy. Holzforschung 45:21-27

Fengel D (1993) Influence of water on the OH valency range in deconvoluted FTIR spectra of cellulose. Holzforschung 47:103-108

Fengel D, Ludwig M (1991) Möglichkeiten und Grenzen der FTIR-Spektroskopie bei der Charakterisierung von Cellulose (Potential and constraints of FTIR-spectroscopy to characterize of cellulose). Das Pap 45:45-51 (in German)

Grabner M, Klein A, Reschreiter H, Barth FE (2010) Wood supply of the bronze age salt mining site at Hallstatt, Austria. In: Anreiter P, Brandstätter K, Goldenberg G, Hanke K, Leitner W, Nicolussi K, 
Pernicka E, Schaffer V, Stöllner T, Tomedi G, Tropper P (eds) Mining in European History and its impact on environment and human societies. University Press, Innsbruck, pp 15-21

Jacomet S, Kreuz A (1999) Archäobotanik (Archaeobotany). Eugen Ulmer, Stuttgart (in German)

Kern A, Kowarik K, Rausch A, Reschreiter H (2009) Kingdom of Salt, 7000 years of Hallstatt. Veröffentlichungen der Prähistorischen Abteilung (VPA) 3, Vienna

Mandl GW, Husen Dv, Lobitzer H (2012) Geologische Karte der Republik Österreich 1:50000. Erläuterungen zu Blatt 96. Bad Ischl. (Geological map of Austria 1:50000. Comments to sheet 96. Bad Ischl). In: Bundesanstalt G (ed) Vienna (in German)

Meder R, Gallagher S, Mackie KL, Böhler H, Meglen RR (1999) Rapid determination of the chemical composition and density of Pinus radiata by PLS modelling of transmission and diffuse reflectance FTIR spectra. Holzforschung 53:261-266

Mohebby B (2008) Application of ATR infrared spectroscopy in wood acetylation. J Agric Sci Technol 10:253-259

Müller G, Schöpper C, Vos H, Kharazipour A, Polle A (2009) FTIR-ATR spectroscopic analyses of changes in wood properties during particle- and fibreboard production of hard- and softwood trees. BioResourse 4:49-71

Pandey KK (1999) A study of chemical structure of soft and hardwood and wood polymers by FTIR spectroscopy. J Appl Polym Sci 71:1969-1975

Pizzo B, Pecoraro E, Alves A, Macchioni N, Rodrigues JC (2015) Quantitative evaluation by attenuated total reflectance infrared (ATR-FTIR) spectroscopy of the chemical composition of decayed wood preserved in waterlogged conditions. Talanta 131:14-20

Rana R, Müller G, Naumann A, Polle A (2008) FTIR spectroscopy in combination with principal component analysis or cluster analysis as a tool to distinguish beech (Fagus sylvatica L.) trees grown at different sites. Holzforschung 62:530-538

Reschreiter H (2013) The prehistoric salt-mines of Hallstatt/Das Salzbergwerk Hallstatt In: Grömer K, Kern A, Reschreiter H, Rösl-Mautendorfer H (eds) Textiles from Hallstatt, Archaeolingua 29, Budapest, pp 13-32

Reunanen M, Ekman R, Heinonen M (1989) Analysis of Finnish pine tar and tar from the wreck of frigate St. Nikolai. Holzforschung 43:33-39

Reunanen M, Ekman R, Heinonen M (1990) Long-term alteration of pine tar in a marine environment. Holzforschung 44:277-278

Rowell RM, Barbour RJ (1990) Archaeological wood. Properties, chemistry and preservation. American Chemical Society, Washington, DC

Schwanninger M, Rodrigues JC, Pereira H, Hinterstoisser B (2004) Effects of short-time vibratory ball milling on the shape of FT-IR spectra of wood and cellulose. Vib Spectr 36:23-40

Sorokin DY, Banciu H, Robertson LA, Kuenen JG, Muntyan MS, Muyzer G (2013) Halophilic and haloalkaliphilic sulfur-oxidizing bacteria. In: Rosenberg E, DeLong EF, Lory S, Stackebrandt E, Thompson F (eds) The prokaryotes. Springer, Berlin, pp 529-554

Stefke B, Windeisen E, Schwanninger M, Hinterstoisser B (2008) Determination of the weight percentage gain and of the acetyl group content of acetylated wood by means of different infrared spectroscopic methods. Anal Chem 80:1272-1279

Stich L (2006) Pinus sylvestris L. Chemische Charakterisierung von rezentem und subfossilem Kiefernholz (Pinus sylvestris L. Chemical characterization of recent and subfossile pine wood). Thesis, University of Natural Resources and Life Sciences, Vienna (in German)

Terpáková E, Kidalová L, Eštoková A, Čigášová J, Števulová N (2012) Chemical modification of hemp shives and their characterization. In: Kluson P (ed) 20th International congress of chemical and process engineering, CHISA 2012, Prague, pp 931-941

Uçar G, Meier D, Faix O, Wegener G (2005) Analytical pyrolysis and FTIR spectroscopy of fossil Sequoiadendron giganteum (Lindl.) wood and MWLs isolated hereof. Holz Roh Werkst 63:57-63 